\title{
Nras in melanoma: Targeting the undruggable target
}

\author{
Mario Mandalà ${ }^{\mathrm{a}, *}$, Barbara Merelli ${ }^{\mathrm{a}}$, Daniela Massi ${ }^{\mathrm{b}}$ \\ ${ }^{a}$ Unit of Medical Oncology, Department of Oncology and Hematology, Papa Giovanni XXIII Hospital, Bergamo, Italy \\ ${ }^{\mathrm{b}}$ Division of Pathological Anatomy, Department of Surgery and Translational Medicine, University of Florence, Italy
}

Accepted 9 May 2014

\section{Contents}

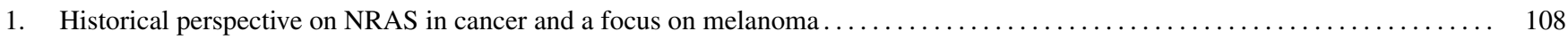

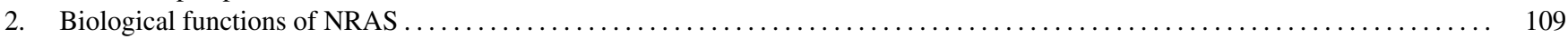

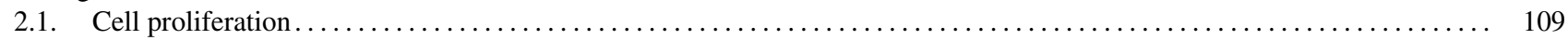

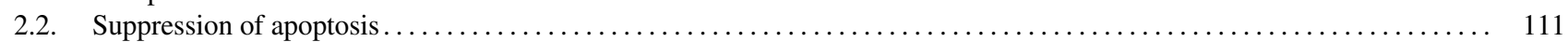

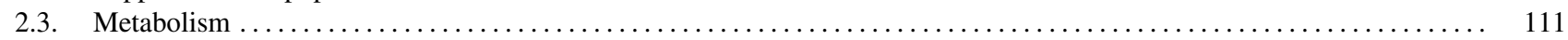

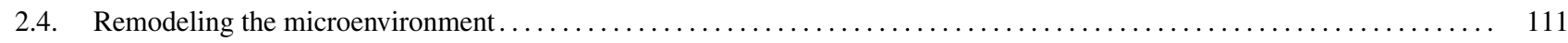

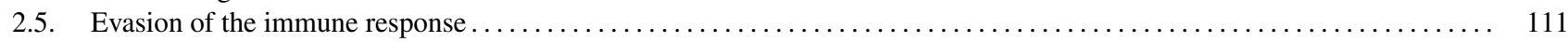

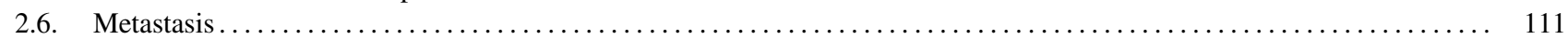

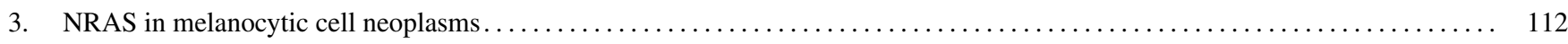

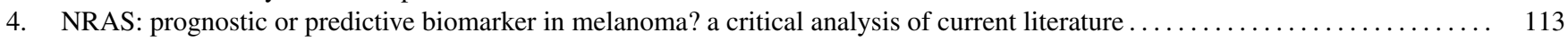

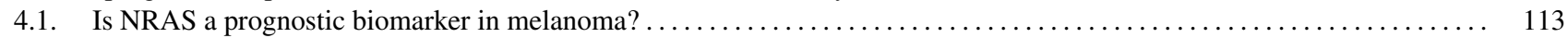

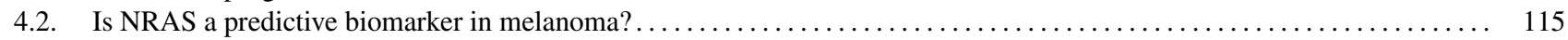

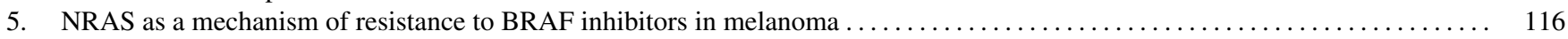

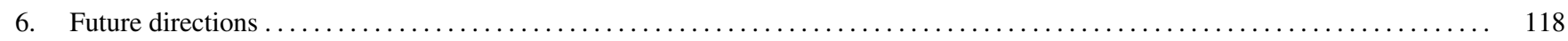

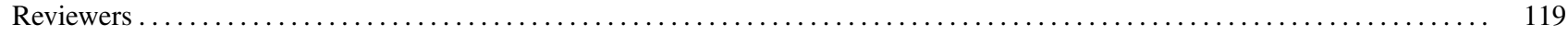

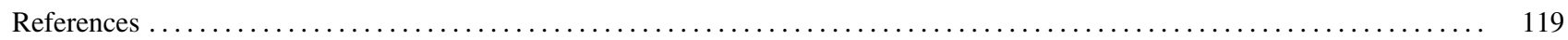

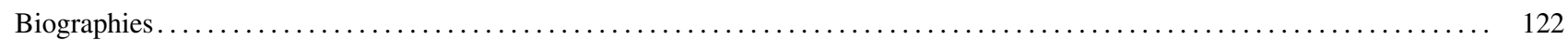

\begin{abstract}
RAS belongs to the guanosine $5^{\prime}$-triphosphate (GTP)-binding proteins' family, and oncogenic mutations in codons 12,13 , or 61 of RAS family occur in approximately one third of all human cancers with N-RAS mutations found in about 15-20\% of melanomas. The importance of RAS signaling as a potential target in cancer is emphasized not only by the prevalence of RAS mutations, but also by the high number of RAS activators and effectors identified in mammalian cells that places the RAS proteins at the crossroads of several, important signaling networks. Ras proteins are crucial crossroads of signaling pathways that link the activation of cell surface receptors with a wide variety of cellular processes leading to the control of proliferation, apoptosis and differentiation. Furthermore, oncogenic ras proteins interfere with metabolism of tumor cells, microenvironment's remodeling, evasion of the immune response, and finally contributes to the metastatic process. After 40 years of basic, translational and clinical research, much is now known about the molecular mechanisms by which these monomeric guanosine triphosphatase-binding proteins promote cellular malignancy, and it is clear that they regulate signaling pathways involved in the control of cell proliferation, survival, and invasiveness. In this review we summarize the biological role of RAS in cancer by focusing our attention on the biological rational and strategies to target RAS in melanoma.
\end{abstract}

(C) 2014 Elsevier Ireland Ltd. All rights reserved.

Keywords: NRAS; Melanoma; Prognostic; Predictive; Resistance

\footnotetext{
* Corresponding author at: Unit of Medical Oncology, Department of Oncology and Haematology, Papa Giovanni XXIII Hospital, Piazza OMS 1, Bergamo 24100, Italy. Tel.: +39035 2673687; fax: +39 0352674985 .

E-mail address: mariomandala@tin.it (M. Mandalà).
} 
Ras proteins are crucial crossroads of signaling pathways that link the activation of cell surface receptors with a wide variety of cellular processes leading to the control of proliferation, apoptosis and differentiation. Furthermore, oncogenic ras proteins interfere with metabolism of tumor cells, microenvironment's remodeling, evasion of the immune response, and finally contributes to the metastatic process.

The importance of RAS signaling as a potential target in cancer is emphasized not only by the prevalence of RAS mutations, but also by the high number of RAS activators and effectors identified in mammalian cells that places the RAS proteins at the crossroads of several, important signaling networks.

After 40 years of basic, translational and clinical research, much is now known about the molecular mechanisms by which these monomeric guanosine triphosphatase-binding proteins promote cellular malignancy, and it is clear that they regulate signaling pathways involved in the control of cell proliferation, survival, and invasiveness. In this review we summarize the biological role of RAS in cancer by focusing our attention on the biological rational and strategies to target RAS in melanoma.

\section{Historical perspective on NRAS in cancer and a focus on melanoma}

Thirty years ago a pioneering study demonstrated that small fragments of DNA from human cancer-derived cells could induce malignant characteristics in mouse fibroblasts [1]. The cellular homolog of an oncogene found in the Harvey rat sarcoma retrovirus (H-RAS) was identified as the DNA sequence responsible for such malignant transformation. A new step in tumor biology had been put in place: this was the first demonstration that human tumors contained activated oncogenes, related to those picked up by retroviruses from their host genomes $[2,3]$. Gene sequencing revealed that the difference between the wild-type (wt) human H-RAS gene and the oncogenic form found in tumors was a single point mutation. Subsequently, three RAS genes and corresponding proteins were described: N-RAS (neuroblastoma-RAS), H-RAS and K-RAS (Kirsten-RAS) [4-6].

RAS belongs to the guanosine $5^{\prime}$-triphosphate (GTP)binding proteins' family. When acted upon by specific factors, such as extracellular ligands that bind specific membrane receptors, these proteins cycle between an activated and inactivated form, RAS-GTP and RAS-GDP, respectively [7]. Activation requires dissociation of protein bound GDP, a process that is accelerated by guanine nucleotideexchange factors (GEFs). This switch-on process involves the reversible exchange of GDP for GTP. The switch-off process is entirely different and involves hydrolysis of GTP to GDP, the guanosine triphosphatase (GTPase) reaction, which is basically irreversible. This process is accelerated by GTPase activating proteins (GAPs) (Fig. 1a).
In physiological conditions, RAS proteins are tethered to the inner cell membrane, coupling growth factor receptors to downstream signaling pathways and regulate important cellular functions such as cell growth, proliferation, and survival. Much is now known about the molecular mechanisms by which these monomeric guanosine triphosphatase-binding proteins promote cellular malignancy, and it is clear that they regulate signaling pathways involved in the control of cell proliferation, survival, and invasiveness.

Mutations at positions 12,13 , or 61 of the H-RAS, NRAS, and K-RAS impair the GTPase activity of the carrier RAS proteins and lock them into a constitutively activated state in which they elicit downstream effectors, even in the absence of ligands that bind specific membrane receptors [8]. This peculiar oncogenic activation - disabling the enzymatic activity - differentiates RAS from other oncogenic kinases such as EGFR or B-RAF, which are typically mutated to produce a hyperactive enzyme.

The importance of RAS signaling as a potential target in cancer is emphasized not only by the prevalence of RAS mutations, but also by the high number of RAS activators and effectors identified in mammalian cells that places the RAS proteins at the crossroads of several, important signaling networks (Fig. 1b).

The first RAS effector identified is the RAF serine/threonine kinase [9-12]. Activation of RAF initiates a phosphorylation cascade that progresses through MEK and ERK (p42/p44 MAPK), and ultimately leads to fine adjustments in downstream targets that regulate cell proliferation, survival, and differentiation [13]. A second RAS effector is the p110 catalytic subunit of the phosphatidylinositol 3kinase (PI3K) [14]. Phosphorylation of phosphatidylinositol by PI3K brings the AKT serine/threonine kinase to the plasma membrane, where it becomes activated and transmits downstream signals to regulate cell survival, protein synthesis, and metabolism [15]. RAF and PI3K are also commonly mutated in melanoma, suggesting that these proteins might be the primary oncogenic effectors of RAS signaling [16].

Interestingly, while mutations in RAF and RAS are generally mutually exclusive, this is not the case for PI3K mutation. These biological differences suggest that endogenous levels of activated RAS do not efficiently activate PI3K signaling, while RAS and RAF mutations appear functionally equivalent. Another explanation is that the RAS/RAF double mutation is lethal for the cell whereas RAS/PI3K are not.

Since oncogenic mutations in codons 12, 13, or 61 of RAS family occur in approximately one third of all human cancers with N-RAS mutations found in about $15-20 \%$ of melanomas, RAS and the signaling pathways under its control have been kept firmly in focus as therapeutic targets (Fig. 2). However, after 40 years of research, many problems remain open. First, what has prevented the development of drugs against RAS?

Several factors have hampered the development of therapies that are able to inhibit RAS in a specific and effective way: (1) the high affinity of RAS for GTP; (2) 
a

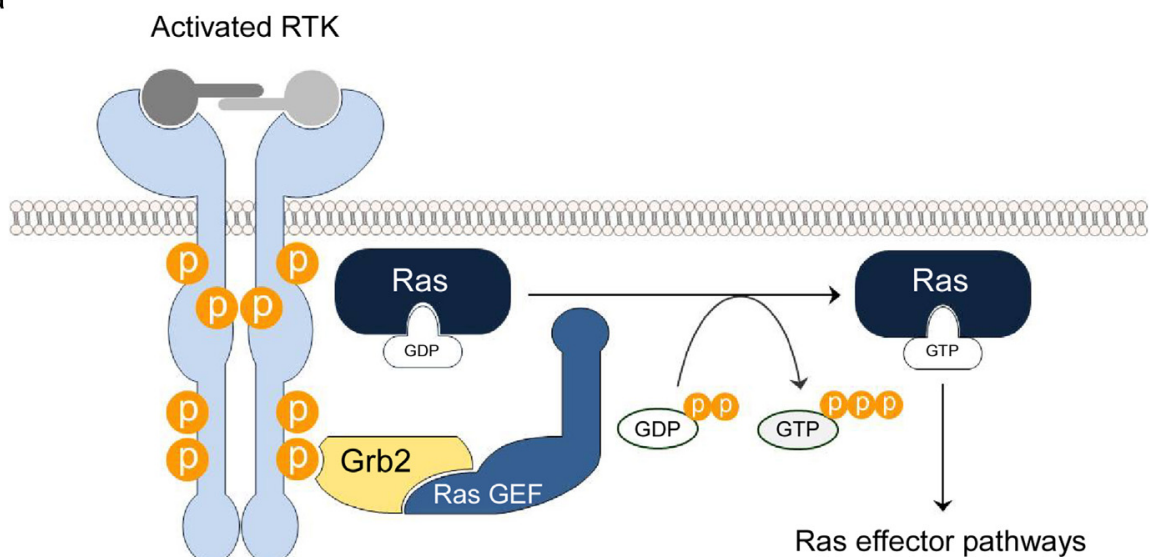

b
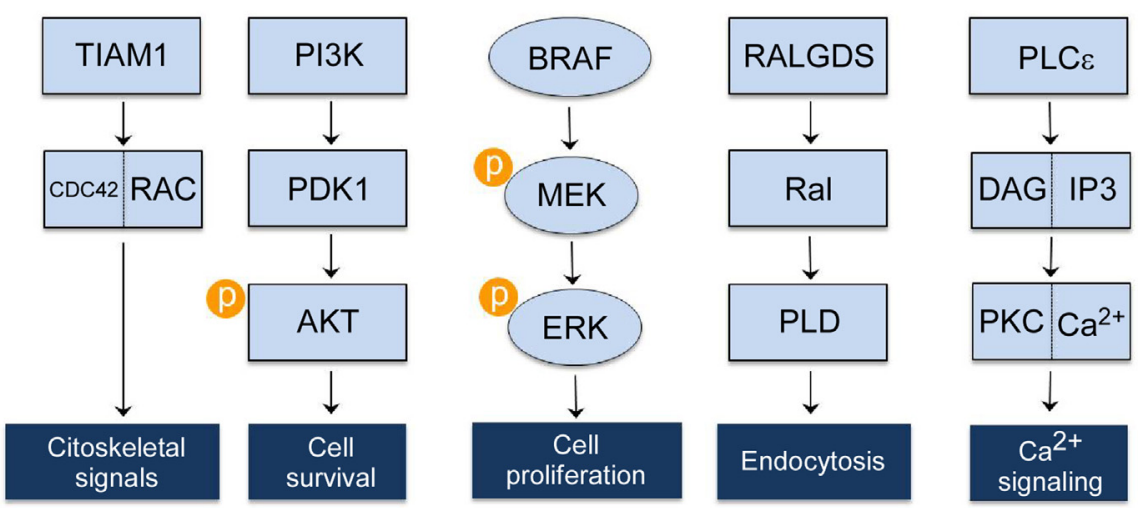

Fig. 1. (a) Mechanism of RAS activation. Receptor tyrosine kinase (RTK)-mediated activation requires dissociation of protein bound GDP, a process that is accelerated by guanine nucleotide-exchange factors (GEFs). This switch-on process involves the reversible exchange of GDP for GTP. The switch-off process is entirely different and involves hydrolysis of GTP to GDP, the guanosine triphosphatase (GTPase) reaction, which is basically irreversible. This process is accelerated by GTPase activating proteins (GAPs). (b) Effectors identified in mammalian cells that place the RAS proteins at the crossroads of several, important signaling networks. (TIAM1: T-cell lymphoma invasion and metastasis 1; PI3K: phosphoinositide 3-kinase; PDK1: phosphoinositide-dependent kinase-1; ERK: extracellular regulated kinase; RALGDS: RAL guanine nucleotide dissociation stimulator; PLD: phospholipase D; PLC $\varepsilon$ : phospholipase C $\varepsilon$; PKC: protein kinase C).

high intracellular concentrations of GTP; (3) the attempt to inhibit farnesylation, a key posttranslational modification step of RAS that is essential for RAS function, through the farnesyltransferase inhibitors (FTIs), was ineffective in clinical trials; (4) targeting mutant N-RAS with siRNA is still limited to preclinical models because of the significant challenge in delivering antisense oligonucleotides in vivo.

In this review we summarize the biological role of RAS in cancer by focusing our attention on the biological rational and strategies to target RAS in melanoma. For this purpose, we performed an extensive "Medline" and Cancerlit literature review (1995-2012). Various combinations of search terms were used depending on the requirements of the database being searched. These terms included "RAS", "MAPK", "target therapy", "MEK" in combination with "cancer patients", "melanoma", "incidence", "pathogenesis", "management", "cancer", "tumors", "resistance", "trials", "prospective", "phase", "retrospective". In addition, we manually researched all relevant review articles and the references of the retrieved papers. Finally, trials were excluded if relevant data could not be extracted.

\section{Biological functions of NRAS}

Ras proteins are crucial crossroads of signaling pathways that link the activation of cell surface receptors with a wide variety of cellular processes leading to the control of proliferation, apoptosis and differentiation (Fig. 3). Furthermore, oncogenic ras proteins interfere with metabolism of tumor cells, microenvironment's remodeling, evasion of the immune response, and finally contributes to the metastatic process.

\subsection{Cell proliferation}

Three decades ago Feramisco et al. demonstrated that oncogenic, mutated forms of ras proteins when introduced 


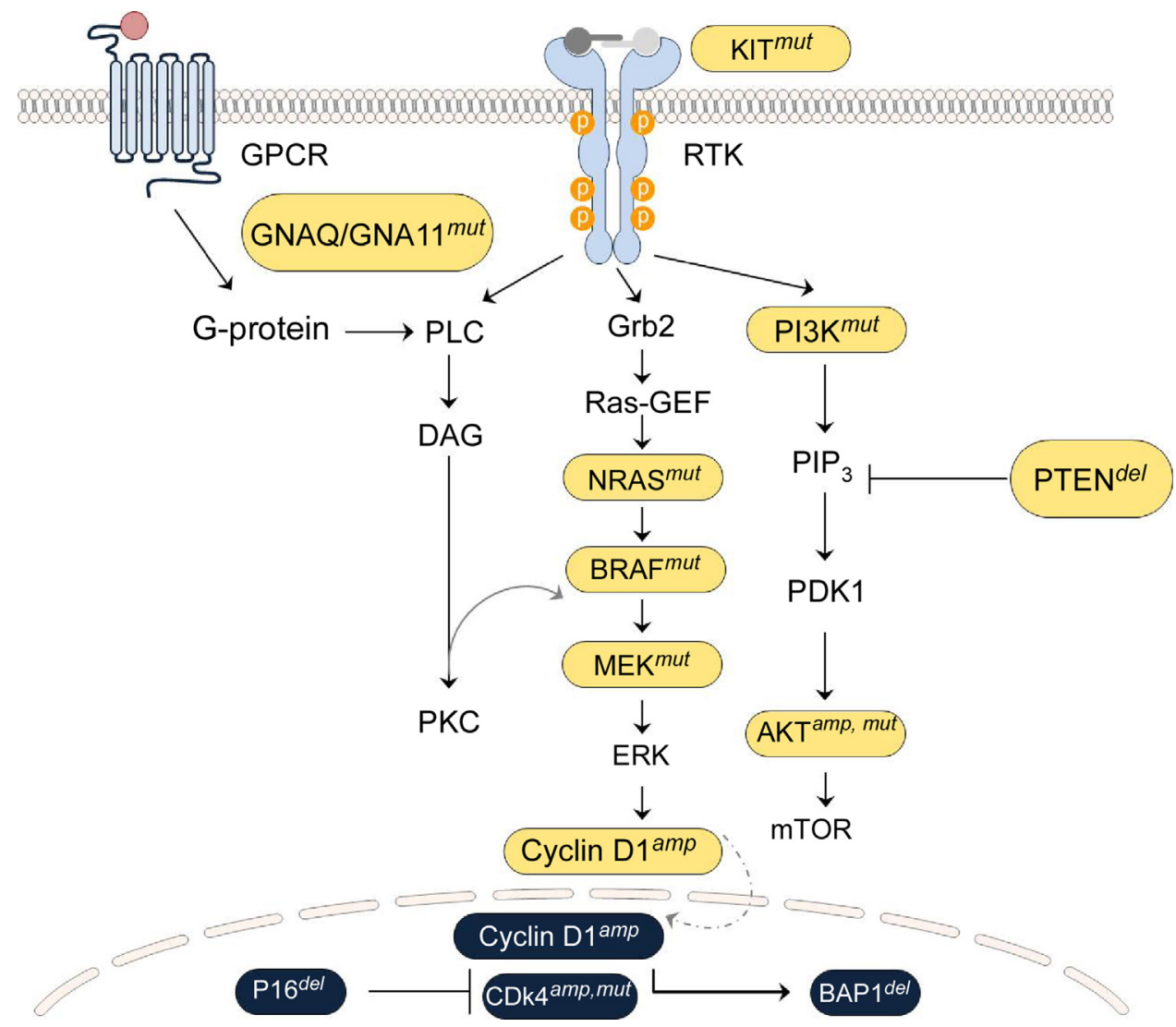

Fig. 2. Potential therapeutics targets in melanoma.

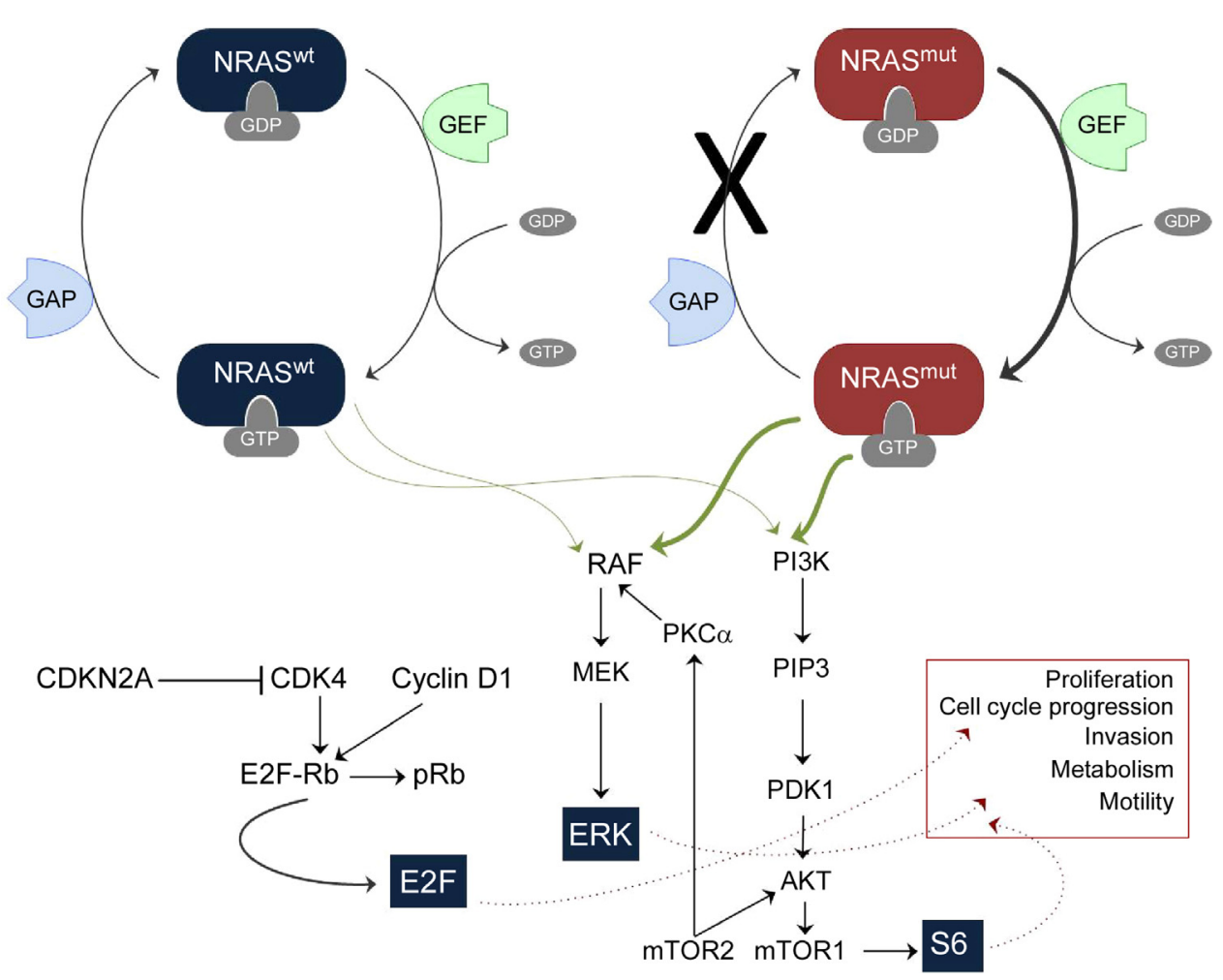

Fig. 3. Ras proteins are crucial crossroads of signaling pathways that link the activation of cell surface receptors with a wide variety of cellular processes leading to the control of proliferation, apoptosis and differentiation. 
by microinjection into a variety of somatic cells determine dramatic morphological changes followed by transient cell proliferation [17]. Proliferation is a check and balances process, being the result of different stimuli, that elicit or inhibit cell cycle [18]. Oncogenic RAS fuels cell proliferation through four distinct biological mechanisms that carry the balance of different stimuli to hang on the side of the cell cycle: upregulation of growth factors, expression of growth factor receptors, upregulation of integrins that promote proliferation and downregulation of anti-proliferative signals. These complex and still unclarified mechanisms lead to activation of several transcription factors such serum response factor (SRF), JUN, activating transcription factor 2 (ATF2) and nuclear factor- $\mathrm{B}(\mathrm{NF}-\kappa \mathrm{B})[19,20]$. In turn, these factors trigger the expression of cyclin D1 [21]. The expression of the G1 cyclin seems a crucial determinant of RAS-induced transformation. It has been reported that cyclin D1-deficient mice are resistant to developing epithelial tumors that are induced by the HRAS oncogene. Pharmacological interference with cyclin D1 or cyclin-dependent kinase inhibitors (CKIs), such as p27 and p21, which would otherwise associate with and inhibit cyclin-dependent kinases (CDKs), could be an exciting avenue of cancer research in the coming years.

\subsection{Suppression of apoptosis}

Oncogenic RAS may have both pro-apoptotic and antiapoptotic functions. The anti-apoptotic function of oncogenic RAS is mediated by several effector pathways, including the RAS-PI3K and the RAS-RAF pathway. Both pathways have been implicated in phosphorylating and inactivating the pro-apoptotic protein BCL-2-associated agonist of cell death (BAD). There is evidence that RAS is implicated in both the development and maintenance of melanoma. In experimental models, melanoma genesis and maintenance are strictly dependent upon expression of HRas V12G and on the opposite HRas V12G down-regulation results in clinical and histological regression of primary and explanted tumors [22]. The initial stages of regression involved marked apoptosis in the tumor cells and host-derived endothelial cells. These data clearly support the hypothesis of an oncogenic RASdriven erosion of the apoptotic pathways and its contribution to melanoma development.

\subsection{Metabolism}

RAS-driven activation of MAPK and PI3K effector pathways stimulate mTOR activity which, in turn, up-regulates the hypoxia-inducible factor $1 \alpha(\mathrm{HIF} 1 \alpha)$, which is well recognized for its ability to stimulate a glycolytic shift [23]. RAS dependent upregulation of HIF $1 \alpha$ enhances the transcription of the glucose transporter GLUT1, thus conferring cells with an increased capacity to take up glucose. In addition, oncogenic RAS leads to an increase in the levels of key glycolytic enzymes [24]. Thus, oncogenic RAS directly contributes to metabolic reactions that stimulate the use of glucose as an anabolic substrate in producing building material for cellular growth. Oncogenic RAS interfaces with cellular metabolism and this interaction increases ultimately the glycolytic rate and cellular viability, supporting tumor growth in vivo [25].

\subsection{Remodeling the microenvironment}

RAS activation sustains pro-angiogenic processes through modulation of endothelial growth factors levels, enhancement of local inflammation and stromal remodeling [26]. RAS upregulates VEGFA via multiple effectors, including, HIF1 $\alpha$, cyclooxygenase 2 (COX2) and prostaglandins' production [27]. Furthermore, RAS-mediated production of pro-inflammatory cytokines, such as IL-6 and IL-8, has emerged as another contributor to the induction of angiogenesis [28]. Finally, upregulation of matrix metalloproteinase 2 (MMP2), MMP9 and urokinase-type plasminogen activator (uPA) has been described [29].

\subsection{Evasion of the immune response}

Oncogenic RAS can disrupt antitumor immunity by essentially two mechanisms: first, by reducing the surface expression of antigen-presenting major histocompatibility complexes (MHC) on tumor cells, resulting in decreased immunogenicity of the RAS-transformed cells [30]. Second, by overcoming host-protecting adaptive immune responses [31]. Upon oncogenic RAS expression, the recruitment of immunosuppressive regulatory $\mathrm{T}$ cells and myeloid-derived suppressor cells at tumor site may lead to a compromised antitumor immune response [32].

\subsection{Metastasis}

Metastasis is a multi-stage process involving a multitude of cellular activities such as cancer cell motility, intravasation, transit in the blood or lymph vessels, extravasation and growth at a new site. RAS promotes these processes by engaging a diverse and broad platform of effector mechanisms. Oncogenic RAS induces alterations in cell-cell and cell-matrix interactions and the acquisition of a migratory phenotype ultimately contributing to the metastatic process. Oncogenic RAS reduces E-cadherin levels and induces the destabilization of E-cadherin - $\beta$-catenin complexes and the $\beta$ catenin relocalization [33]. In addition, oncogenic RAS contributes to the enhanced motility of tumor cells by affecting changes in the polymerization, organization and contraction of actin; the polymerization and/or stability of microtubules; and the transcriptional regulation of mitogenic gene products [34]. Oncogenic RAS protects tumor cells from matrix deprivation-induced apoptosis, or anoikis thereby contributing to their capacity of migration through the circulatory system [33-35]. 


\section{NRAS in melanocytic cell neoplasms}

One of the unresolved issues concerning the oncogenic activation of RAS pertains to whether specific oncogenic outputs are driven by mutations in a particular RAS isoform. This hypothesis is supported by the well-recognized nonrandom distribution pattern of activated isoforms of RAS among different cancer types.

NRAS mutations have been found in approximately 15-20\% of human melanomas while HRAS and KRAS mutations are rare (1\%) [36]. A rational explanation for the greater occurrence of NRAS mutations relies on distinct differences between the signaling capabilities of NRAS and KRAS in melanocytes [37]. When the transformation efficiencies of mutant NRAS and KRAS were compared in immortal, non-transformed Ink4a/Arf-deficient melanocytes, it was shown that in contrast to KRAS mutation, NRAS mutation leads to increased cellular proliferation and is more potently tumorigenic [37]. Furthermore, NRAS mediates activation of both MAPK and PI3K/AKT/MYC signaling. Specifically, although both NRAS and KRAS efficiently activate the classical MAPK pathway, only NRAS effectively prevents glycogen synthase kinase3 (GSK3)-mediated phosphorylation of Myc via PI3K/AKT, which results in enhanced activity of endogenous Myc protein [37]. In contrast to KRAS, NRAS and HRAS also show a more potent activation of PI3K/AKT likely due to the fact that both NRAS and HRAS colocalize to lipid rafts, whereas KRAS is excluded from lipid rafts and localizes to the disordered plasma membrane [38], resulting in a less efficient activation or a limited access to a defined subset of downstream effector proteins.

There is a great debate whether specific RAS isoforms dictate specific clinico-pathological melanocytic cell neoplasms. An extraordinarily high NRAS mutation frequency seems to be characteristic of medium-sized $(\geq 1.5 \mathrm{~cm})$ and large-giant congenital nevi whereas common acquired nevi and Spitz nevi have rare NRAS mutations ( $4.6 \%$ and $4 \%$, respectively) [39].

The frequency of NRAS mutations in medium-sized congenital nevi is $64-70 \%$ [39-41] and raises to $94.7 \%$ in large-giant congenital nevi where it has been recently recognized as the sole recurrent somatic mutation [42]. It has been suggested that NRAS mutations exert stronger growth signals, resulting in the formation of larger nevi than those linked to BRAF mutations [43]. In contrast, small congenital nevi $(<1.5 \mathrm{~cm})$ are genetically similar to common acquired nevi and tend to show a lower incidence of NRAS mutations and higher incidence of BRAF mutations [40]. In addition, it has been reported that nevi that display histological features frequently found in nevi present at birth (so-called "congenital pattern nevi") but lack a definitive history of presence at birth showed only $25 \%$ of NRAS mutations and $71 \%$ of BRAF mutations [44]. NRAS mutations were also found in $48 \%$ to $70 \%$ of proliferative nodules that developed within congenital nevi early in life, but the presence of such mutations does not seem to confer an increased risk of malignant transformation $[44,45]$.

Recently, different studies have demonstrated that early embryonic/post zygotic somatic mutations in the NRAS gene are implicated in the development of neurocutaneous melanocytosis, a rare congenital disorder, in which affected patients have an increased number of melanocytes in the leptomeninges and the skin, with a large congenital melanocytic nevus usually associated with so-called "satellites" in the vicinity, and childhood melanoma of the central nervous system [46-48]. In line with these observations, recently it has been shown that primary melanoma of the CNS in children carries oncogenic mutations in NRAS, unlike primary melanoma of the central nervous system in adults, in which NRAS is not a common driver oncogene [46].

So-called "dysplastic nevi" do not seem to carry NRAS mutations [49-51]. However, in another study 5/7 "dysplastic nevi" from individuals with a hereditary predisposition to melanoma (who carried germline CDKN2A mutations) were reported to be NRAS mutated and it was suggested that NRAS mutations are implicated during early melanoma development [52]. Overall, given the limited number of cases analyzed and the lack of interobserver agreement for the morphology-based diagnosis of "dysplastic nevi" it is too early to draw significant conclusions. A recent study has shown that nevus-associated melanomas show a similar frequency of BRAFV600-and NRASQ61-mutations compared to published reports of melanomas of the skin in general [53]. Such results do not support the concept that oncogenic BRAF or NRAS mutations play a major role in the development of melanoma from nevi and do not sustain the multistep theory of melanoma progression from a benign melanocytic nevus through "dysplastic nevus" and eventually to melanoma [53].

RAS has been extensively investigated in melanoma and several studies have assessed whether specific RAS isoforms correlate with race, pattern of sun exposure, clinical presentation, and conventional morphological features, which are commonly reported in histopathological reports.

NRAS is mutated in approximately $15-20 \%$ of primary cutaneous melanomas in Caucasian patients [54-58]. In black Africans and Asian populations there is a lower frequency (12\% and $7.2 \%$, respectively) $[59,60]$. Patients with NRASmutated melanomas were reported to be older in comparison with individuals with BRAF-mutated tumors [61] although in a recent meta-analysis on 31 studies involving 1972 patients, no association between age and NRAS mutations was found [55]. Similarly, no correlation was found between gender and NRAS mutations [58].

In most studies, NRAS mutation was significantly more frequent in melanomas arising in chronic sun-damaged skin $[55,62]$. The incidence of the NRAS mutation according to tumor site was highest in the extremities (25\%), followed by the face or scalp $(18 \%)$ and trunk $(18 \%)[55,61,63]$. NRAS mutations have also been found in conjunctival melanomas (18\% frequency) [63], sinonasal melanomas (22\%) [65], esophageal melanomas (37.5\%), including mutations in exon 
1 , which is a rare mutation site for cutaneous melanoma [66]. Interestingly, melanoma of unknown primary sites showed NRAS mutations in $32 \%$ of cases associated with high somatic mutation rates, high ratios of $\mathrm{C}>\mathrm{T} / \mathrm{G}>\mathrm{A}$ transitions, and a $45 \%$ of BRAF mutations, collectively indicating a mutation profile consistent with cutaneous sun-exposed melanomas [67].

NRAS mutations are overall more frequently evident in patients with nodular melanoma [55]. From $25 \%$ to $31 \%$ of NRAS mutations occurred in this melanoma subtype $[55,59,68]$. A higher incidence of NRAS mutations was found in non-acral fast growing melanomas in comparison with non-fast growing melanomas (26.5 versus $12.1 \%$ ) [69].

While in some studies NRAS mutated melanomas were reported to be significantly thicker and higher Clark's level than wt tumors $[61,62,64,68]$ other reports could not confirm any association between NRAS mutation and tumor thickness $[70,71]$. Ulceration was reported to be lower in NRAS-mutated tumors in comparison to BRAF mutated tumors (9.7 versus $22.4 \%$, respectively) [63] but no obvious effect of mutational status on the presence of ulceration was reported by others [68]. Melanomas harboring NRAS mutations have shown greater mitotic rates than BRAF mutant melanomas $[63,68]$.

In conclusion, the retrospective nature of the studies and the heterogeneity of patients' populations may explain the different results obtained so far, and it should be acknowledged that phenotypic-genotypic correlations in melanoma is still a work in progress.

\section{NRAS: prognostic or predictive biomarker in melanoma? a critical analysis of current literature}

The prognostic and predictive significance of NRAS in melanoma is still a matter of intense debate.

A biomarker is, by definition, an objectively measured and evaluated parameter that provides information on the natural history of a specific disease, its pathogenic process or on pharmacological responses to a specified therapeutic intervention. A prognostic biomarker provides information on overall cancer outcome, regardless of therapy. In the medical literature two types of prognostic biomarkers have been reported: biomarkers that give information on recurrence in patients who receive curative treatment and those that correlate with the median overall survival (OS) in patients with metastatic disease. According to a NIH Consensus Conference, a clinical useful prognostic marker must be a proven independent, significant factor, that is easy to determine and interpret and has therapeutic consequences [72].

Prognostic biomarkers that provide information on the risk of relapse are important not only to better stratify patients in clinical trials but also to spare many patients the treatmentrelated toxicity without compromising survival. A biomarker with predictive value gives information on the effect of a therapeutic intervention in a patient. Two types of predictive biomarkers have been reported: (1) upfront and (2) early predictive markers. The first can be used for patient selection and the second provides information early during therapy. The latter biomarker is less useful than the former because does not provide reliable and useful information to select the best strategy to be adopted before starting therapy.

\subsection{Is NRAS a prognostic biomarker in melanoma?}

Several studies have been carried out to examine whether mutations in NRAS confer different pathological features and clinical behavior. The effect of these mutations on clinical outcome remains uncertain $[59,61,73,74]$. Table 1 summarizes most important studies on the prognostic role of NRAS in melanoma $[63,68,74-79,61,80-83]$. The majority of these studies have been retrospective in nature, and most of them included patients with recurrent or metastatic disease.

When OS was measured from the time of primary tumor, NRAS mutations were found to have no impact on OS $[59,63,61]$. Akslen et al. evaluated 51 primary nodular melanomas. In this retrospective study NRAS mutation was found in $27 \%$ of patients [82]. RAS mutation was not associated with tumor cell proliferation by Ki-67 expression, tumor thickness, microvessel density, or vascular invasion, and there were no differences in patient survival [82].

In an attempt to correlate BRAF and NRAS mutational status with features known to influence tumor behavior, including age, gender, Breslow depth, Clark level, mitotic rate, the presence of ulceration, and AJCC staging, Ellerhorst et al. performed a study on 223 microdissected primary melanomas [63]. Patients whose tumors carried either mutation presented with more advanced stages compared to patients with wt tumors, and specifically, were more likely to have Stage III disease at diagnosis. BRAF and NRAS mutations did not influence survival. Furthermore, in this study survival did not differ between Stage III patients whose primary tumors do or do not carry mutations, even though the mutated tumors tended to produce larger volume nodal disease [63].

Recently, Devitt et al. reported data obtained from a prospective cohort of 249 patients [67]. When compared to wt NRAS patients, multivariate analysis of melanoma-specific survival identified NRAS mutations as an adverse prognostic factor. However in the multivariate analysis, there was no evidence that NRAS mutation was neither an independent predictor of relapse free survival (RFS) nor of OS [68].

However, in two studies where OS was measured from the time of biopsy of advanced disease, NRAS mutations were associated with improved OS when compared to tumors with BRAF mutations or both BRAF/NRAS wt tumors $[73,74]$.

Mann et al. performed a comprehensive clinicopathological assessment of fresh-frozen macroscopic nodal metastases and the preceding primary melanoma, somatic mutation profiling, and gene expression profiling to identify determinants of outcome in 79 melanoma patients [81]. The authors found that the absence of BRAF mutation or 
Table 1

Summary of most significant studies addressing the prognostic significance of NRAS mutations in melanoma.

\begin{tabular}{|c|c|c|c|c|c|c|c|}
\hline Author & Patients no. & Stage & $\begin{array}{l}\text { Site of primary } \\
\text { melanoma }\end{array}$ & Genes & Exons & PFS & OS \\
\hline Demunter (2001) [75] & 81 & All stages & Skin & NRAS & 1 & $p=0.0130$ & - \\
\hline Omholt (2002) [78] & 72 & All stages & Skin & NRAS & $\begin{array}{l}2 \\
3\end{array}$ & - & NS \\
\hline Houben (2004) [76] & 174 & All stages & Skin & $\begin{array}{l}\text { BRAF } \\
\text { NRAS }\end{array}$ & $\begin{array}{l}15 \\
11 \\
1 \\
2\end{array}$ & NS & $\begin{array}{l}\text { NS } \\
p=0.02^{\mathrm{a}}\end{array}$ \\
\hline Akslen (2005) [81] & 57 & All stages & Skin & $\begin{array}{l}\text { BRAF } \\
\text { NRAS }\end{array}$ & $\begin{array}{l}15 \\
11 \\
2 \\
1\end{array}$ & - & NS \\
\hline $\begin{array}{l}\text { Edlundh-Rose (2006) } \\
\text { [79] }\end{array}$ & 219 & NA & Skin & $\begin{array}{l}\text { BRAF } \\
\text { NRAS }\end{array}$ & $\begin{array}{l}15 \\
11 \\
2\end{array}$ & - & NS \\
\hline Ugurel (2007) [73] & 109 & $\begin{array}{l}\text { III } \\
\text { IV }\end{array}$ & $\begin{array}{l}\text { Skin } \\
\text { Mucosa } \\
\text { Occult } \\
\text { NA }\end{array}$ & NRAS & $\begin{array}{l}15 \\
11\end{array}$ & - & $p=0.006$ \\
\hline Ellerhorst (2010) [62] & 223 & I-III & Skin & $\begin{array}{l}\text { BRAF } \\
\text { NRAS }\end{array}$ & $\begin{array}{l}15 \\
2\end{array}$ & - & NS \\
\hline Devitt (2011) [67] & 244 & I-III & Skin & $\begin{array}{l}\text { BRAF } \\
\text { NRAS }\end{array}$ & $\begin{array}{l}15 \\
3\end{array}$ & - & $\begin{array}{l}p=0.04 \\
\text { (MSS) }\end{array}$ \\
\hline Jakob (2012) [77] & 667 & All stages & $\begin{array}{l}\text { Skin } \\
\text { Mucosa } \\
\text { Uvea } \\
\text { Occult }\end{array}$ & NRAS & $\begin{array}{l}1 \\
2\end{array}$ & - & $p=0.004$ \\
\hline Mann (2012) [80] & 79 & III & Skin & $\begin{array}{l}\text { BRAF } \\
\text { NRAS }\end{array}$ & $\begin{array}{l}15 \\
2\end{array}$ & - & NS \\
\hline Bucheit (2013) [61] & 438 & IV & $\begin{array}{l}\text { Skin } \\
\text { Mucosa } \\
\text { Soft parts } \\
\text { Occult }\end{array}$ & NRAS & $\begin{array}{l}1 \\
2\end{array}$ & - & NS \\
\hline Birkeland (2013) [74] & 85 & $\begin{array}{l}\text { III } \\
\text { IV }\end{array}$ & $\begin{array}{l}\text { Skin } \\
\text { Mucosa } \\
\text { Uvea } \\
\text { Occult }\end{array}$ & NRAS & 3 & $p<0.01$ & $p<0.001$ \\
\hline Ekedahl (2013) [82] & 203 & IV & Skin & $\begin{array}{l}\text { BRAF } \\
\text { NRAS }\end{array}$ & $\begin{array}{l}15 \\
2\end{array}$ & - & $p=0.25$ \\
\hline
\end{tabular}

OS: overall survival; PFS: progression free survival; MSS: melanoma-specific survival; NS: not significant.

${ }^{\text {a }}$ OS from metastasectomy.

NRAS mutation was independently associated with better survival. Furthermore, a 46-gene expression signature with strong overrepresentation of immune response genes was predictive of better survival; in the full cohort, median survival was $>100$ months in those with the signature, but 10 months in those without.

Recently, in a retrospective study, Jacob et al. tested for NRAS 677 patients with metastatic melanoma to identify 
Table 2

Studies reporting on RAS mutations as predictive biomarkers in melanoma.

\begin{tabular}{|c|c|c|c|c|c|c|c|c|c|c|}
\hline \multicolumn{11}{|c|}{ RAS as predictive biomarker in melanoma } \\
\hline Author & $\begin{array}{l}\text { Patients } \\
\text { no. }\end{array}$ & Stage & $\begin{array}{l}\text { Site of } \\
\text { primary } \\
\text { melanoma }\end{array}$ & Genes & Mutations & Drug (s) & OS & PFS & TTP & $\mathrm{CCR} / \mathrm{CB}$ \\
\hline \multirow{2}{*}{$\begin{array}{l}\text { Banerji (2008) } \\
\text { [83] }\end{array}$} & 6 & NR & NR & BRAF & V600E & 17-AAG & NR & - & NR & NR \\
\hline & & & & NRAS & G13D & 17-AAG & & & & \\
\hline \multirow{5}{*}{$\begin{array}{l}\text { Joseph (2012) } \\
\text { [84] }\end{array}$} & 208 & IIIc & NR & BRAF & V600 & HD IL2 & NS & NS & - & - \\
\hline & & IV & & & & & NS & NS & & $p=0.05$ \\
\hline & & & & NRAS & G12 & HD IL2 & & & & \\
\hline & & & & & G13 & & & & & \\
\hline & & & & & Q61 & & & & & \\
\hline \multirow{4}{*}{$\begin{array}{l}\text { Birkeland (2013) } \\
\text { [74] }\end{array}$} & 85 & III & Skin & NRAS & G12 & DTIC & $p<0.001$ & NS & - & NS \\
\hline & & IV & Mucosa & & G13 & & & & & \\
\hline & & & Uvea & & & & & & & \\
\hline & & & Occult & & & & & & & \\
\hline \multirow[t]{5}{*}{ Patelet (2013) [85] } & 18 & III & Skin & BRAF & V600E & S. +/-DTIC, & NR & - & NS & NS \\
\hline & & IV & & & R603 & TXT, E. or T. & & & & \\
\hline & & & & NRAS & Q61R & S. +/-DTIC, & & & & \\
\hline & & & & & Q61K & TXT, E. or T. & & & & \\
\hline & & & & & G12S & & & & & \\
\hline
\end{tabular}

17-AAG: HSP90 inhibitor 17-allylamino-17-demethoxygeldanamycin; DTIC: dacarbazine; CB: clinical benefit: objective response or stable disease recorded 3 months after DTIC treatment; HD IL2: high-dose interleukin 2; CRR: clinical response rate; TTP: time to progression; NR: not reported; S.: selumetinib; TXT.: docetaxel; E.: erlotinib; T.: temsirolimus.

significant associations of mutation with tumor and patient characteristics and with survival from the diagnosis of stage IV disease [78]. Tumor mutation status was associated with the risk of central nervous system involvement at the diagnosis. Patients with NRAS mutations had a median survival of 8.2 months from stage IV diagnosis, which was shorter than the median survival of wt patients (15.1 months). At multivariate analysis, after adjusting for age, sex, metastatic site, serum lactate dehydrogenase level, NRAS mutation was independently associated with decreased OS.

Overall, the results published so far are heterogeneous in terms of patients' selection criteria and methodology. Specifically, difficulties in comparing results arise from the following considerations: (i) most of the available data are retrospective; (ii) patients with different tumor stages have been evaluated; (iii) primary or metastatic sites have been tested; (iv) different tumor histotypes have been included.

Hence, there is no definitive evidence that NRAS mutation is prognostic in patients with limited radically resected disease (stages I-III) or in metastatic setting. Furthermore, most of the observations have been conducted in Caucasian populations with scarcity of data from other geographic areas (e.g. Asian).

\subsection{Is NRAS a predictive biomarker in melanoma?}

The RAS mutational status does not give information on the effect of a therapeutic intervention in a patient, hence it is not a predictive marker either upfront or as early predictive marker. Table 2 includes studies addressing the predictive significance of NRAS mutations in melanoma [75,84-86].

So far, several different strategies of directly targeting RAS have not resulted in effective therapeutics. There is evidence that some NRAS-mutated cell lines are sensitive to MEK inhibition in vitro [87]. However, in this model, the sensitivity to the MEK inhibitor of N-RAS mutated cells was significantly lower than those harboring BRAF mutation.

The lower activity of MEK inhibitors in N-RAS-mutated in comparison with BRAFV600-mutated melanoma cells may be explained by the complexity of pathways with which RAS interacts within the cell.

It is well known that RAS family members have multiple other targets, such as PI(3)K and RalGDS; these may exert more prominent oncogenic effects in certain tumor subtypes, thereby reducing the requirement for MAPK activation. Hence, single-agent therapeutic strategies may prove insufficient in RAS mutant tumors. Instead, direct RAS inhibitors or combinatorial strategies may be required.

Recently, an oral MEK inhibitor (MEK162) was tested in patients with metastatic melanoma harboring BRAF or NRAS mutations with encouraging results in NRAS mutated patients [88]. In preclinical models MEK162 inhibited growth of NRAS-mutated and Val600Glu BRAF-mutated melanoma in studies that used in vitro and in vivo models [89].

However, the response rate was reported in only $20 \%$ of patients and only in $10 \%$ of this population the response was confirmed. Furthermore, the median progression-free survival (PFS) was 3.7 months and the median duration of 
response was 7.6 weeks [88]. These data clearly indicate that most of the patients rapidly develop resistance to the MEK inhibitor.

A two-arm, randomized, prospective, open-label, multicenter, phase III study to compare the efficacy and safety of MEK162 (45 mg bis in die) versus dacarbazine $(1000 \mathrm{mg} / \mathrm{m} 2$ IV every 3 weeks) in patients with advanced (Stage IIIC) unresectable or metastatic (Stage IV) NRAS Q61 mutationpositive cutaneous melanoma is currently underway. The primary end point of the study is progression-free survival, while secondary end point is overall survival ("NEMO trial" NCT01763164).

Another second generation MEK inhibitor, selumetinib, demonstrated marked inhibition of pERK, either in cell lines harboring BRAF mutations as well as in those harboring NRAS mutations [90].

A randomized phase II study comparing the MEK inhibitor Pimasertib (AS703026) with dacarbazine in previously untreated subjects with N-Ras mutated locally advanced or metastatic malignant cutaneous melanoma is currently under way (NCT01693068).

At the time of the publication of this manuscript there are no randomized clinical trials comparing MEK162 with other MEK inhibitors in NRAS mutated melanoma patients.

Recently the development of small molecules that irreversibly bind to a common oncogenic mutant, K-Ras(G12C) has been reported [91]. These compounds rely on the mutant cysteine for binding and therefore do not affect the wt protein. These inhibitors to K-Ras $(\mathrm{G} 12 \mathrm{C})$ subvert the native nucleotide preference to favor GDP over GTP and impairing binding to Raf. These findings are relevant since they reveal, for the first time, a new allosteric regulatory site on Ras that is targetable in a mutant-specific manner.

A subgroup of melanomas with RAS dependence is those with low-activity.

BRAF mutations, such as those found at positions 466 , 464 and 597. Cell lines with low-activity BRAF mutations show an impaired activation of MAPK signaling in isolated kinase assays and often harbor concurrent NRAS mutations at positions 12 and 13. It cannot be excluded that NRAS melanoma cells with low activity mutant BRAF may partially explain the sensitivity of a subgroup of NRAS melanoma cells to MEK inhibitors.

In accordance with this hypothesis, Dahlman et al. performed an analysis of BRAF exon 15 in 49 tumors with lack of BRAFV600 mutation and showed that 2 (4\%) harbored L597 mutations and other 2 BRAF D594 and K601 mutations [92]. In vitro signaling induced by L597 mutants was suppressed by MEK inhibition. A patient with BRAF L597S mutant metastatic melanoma responded significantly to treatment with the MEK inhibitor, TAK-733. Collectively, these data show clinical significance response to BRAF(L597) mutations in melanoma.

The focus of indirect RAS inhibition has then shifted to interfere with the complex network of activated downstream cascades such as the MAPK, phosphoinositol 3-kinase (PI3K), phospholipid C (PLC), RalGEF.

Posch et al. evaluated the sensitivity of RAS mutated melanoma cells and xenografts to MEK and PI3K inhibitors [93]. NRAS mutated cells were more sensitive to MEK inhibition compared with the PI3K/mTOR cascade inhibition. Combined targeting of MEK and PI3K was superior to MEK and mTOR inhibition in all NRAS mutant melanoma cell lines, suggesting that PI3K signaling is more important for cell survival in NRAS mutant melanoma when MEK is inhibited. However, targeting of PI $3 \mathrm{~K} / \mathrm{mTOR}$ in combination with MEK inhibitors is necessary to effectively abolish growth of NRAS mutant melanoma cells in vitro and regress xenografted NRAS mutant melanoma. In this model MEK and PI3K/mTOR inhibition was synergistic. These results indicate that combined targeting of the MEK/ERK and PI3K/mTOR pathways has antitumor activity and could be a valid option in the treatment of NRAS mutant melanoma, for which there are currently no effective therapies.

Finally, Johnson et al. reported that patients with NRAS mutated metastatic melanoma achieve increased clinical benefit from immunotherapy compared to those with BRAF/NRAS wt [94].

These data suggest that NRAS mutation status may be a biomarker of response to immunotherapy in metastatic melanoma and that molecularly targeted immunotherapy may be feasible. However a larger, prospective analysis is necessary to validate and expand on these results, including those with BRAF mut and KIT mut metastatic melanoma to draw firm conclusions.

Overall, the above data suggest that: (i) a subgroup of NRAS mutated melanoma may be sensitive to MEK inhibition but in most cases resistance rapidly occur; (ii) a subgroup of NRAS mutated melanoma harbor low activity BRAF mutation, and the meaning of these mutations should be further investigated; (iii) single-agent therapeutic strategies may prove insufficient in RAS mutant tumors. Instead, combinatorial strategies may be required to overcome resistance.

\section{NRAS as a mechanism of resistance to BRAF inhibitors in melanoma}

A high percentage of patients with BRAFV600E mutant melanomas respond to selective RAF inhibitors but resistance eventually emerges.

Unlike what happens in other tumors where additional mutations eventually occur in the target (EGFR in non-small cell lung cancer, c-KIT in GISTs, BCR-ABL in chronic myeloid leukemia) the early evidence from direct sequencing of BRAF exons suggests that new point mutations are not evident and that BRAFV600E persists.

RAS has been consistently described as a mechanism of resistance to BRAF inhibitors. It is well known that there is a switch in RAF isoform usage depending on whether BRAF or RAS is mutated (Table 3) [95-101]. In melanocytes in 
Table 3

Resistance to BRAF inhibitors.

\begin{tabular}{|c|c|c|c|c|}
\hline \multicolumn{5}{|c|}{ Resistance to BRAF inhibitors } \\
\hline Author & $\begin{array}{l}\text { Patients with acquired } \\
\text { resistance to therapy no. }\end{array}$ & Drug & Mechanism of resistance & $\begin{array}{l}\text { NRAS acquired } \\
\text { mutations patients no. }(\%)\end{array}$ \\
\hline Nazarian (2010) [95] & 12 & Vemurafenib & $\begin{array}{l}\text { NRAS codon } 61 \\
\text { mutations } \\
\text { PDGFRB overexpression }\end{array}$ & $1(8.3 \%)$ \\
\hline Trunzer (2013) [96] & 13 & Vemurafenib & $\begin{array}{l}\text { Increased pERK levels } \\
\text { MEK1 mutations } \\
\text { NRAS codon } 61 \\
\text { mutations }\end{array}$ & $3(23 \%)$ \\
\hline McArthur (2011) [97] & 11 & Vemurafenib & $\begin{array}{l}\text { NRAS codon } 61 \\
\text { mutations }\end{array}$ & $1(9.09 \%)$ \\
\hline Poulikakos (2011) [98] & 19 & Vemurafenib & $\begin{array}{l}\text { Increased RAS-GTP } \\
\text { levels } \\
\text { Increased } \\
\text { RAS-independent RAF } \\
\text { dimerization }\end{array}$ & $6(31.6 \%)$ \\
\hline Wagle (2014) [99] & 5 & $\begin{array}{l}\text { Dabrafenib } \\
\text { Trametinib }\end{array}$ & $\begin{array}{l}\text { Mutation in MEK2 } \\
\text { BRAF splice isoform } \\
\text { BRAF amplification }\end{array}$ & $5(100 \%)$ \\
\hline Van Allen (2014) [100] & 30 & $\begin{array}{l}\text { Vemurafenib } \\
\text { Dabrafenib }\end{array}$ & $\begin{array}{l}\text { MAPK pathway } \\
\text { Alterations } \\
\text { MEK1 Mutations } \\
\text { MEK2 Mutations } \\
\text { MIFT Amplification }\end{array}$ & $23 / 45(51 \%)$ \\
\hline Rizos (2014) [101] & 38 & & $\begin{array}{l}\text { Mutation in MEK2 } \\
\text { Mutation in MEK1 } \\
\text { Mutation in NRAS } \\
\text { Mutation in AKT } \\
\text { BRAF splice isoform } \\
\text { BRAF amplification }\end{array}$ & $3(8 \%)$ \\
\hline
\end{tabular}

which BRAF is mutated, BRAF is primarily responsible for signaling to MEK and ERK. In presence of RAS mutation an excessive ERK signaling through BRAF and in general MAPK activation would induce cell cycle arrest or senescence through transcriptional up-regulation of proteins such as p21, p27, and p16 ${ }^{\mathrm{INK} 4 \mathrm{~A}}[102]$. To avoid this, the cells switch to CRAF, which provides weaker signaling and is compatible with tumor progression.

Nazarian et al. demonstrated that high levels of activated N-RAS resulting from mutations lead to significant MAPK pathway reactivation upon BRAF inhibitor treatment [95]. In a series of elegant experiments, knockdown of NRAS reduced growth of the respective BRAF inhibitors resistant cells. On the opposite, overexpression of N-RAS conferred BRAF inhibitor resistance to BRAF inhibitor sensitive parental cell lines.

Recently, Su et al. used cell lines to establish BRAFV600E melanoma clones with acquired resistance to a BRAF inhibitor [103]. The authors confirmed that no second-site mutations could be identified in the BRAF coding sequence. In this model, resistance correlated with increased levels of RAS-GTP, and sequencing of RAS genes revealed a rare activating mutation in KRAS, resulting in a $\mathrm{K} 117 \mathrm{~N}$ change in the KRAS protein. Elevated levels of CRAF and phosphorylated AKT were also observed. Interestingly, combination treatment with BRAF inhibitor and either a MEK inhibitor or an AKT inhibitor synergistically inhibited proliferation of resistant cells. These data support clinical studies in which combination therapy with other targeted agents are being strategized to overcome resistance.

Trunzer et al. [96] evaluated serial biopsies to study changes in mitogen-activated protein kinase (MAPK) signaling, cell-cycle progression, and factors causing intrinsic or acquired resistance by immunohistochemistry, DNA sequencing, or somatic mutation profiling to a BRAF inhibitor within the BRIM 2 study [104]. In this study 3/13 patients had NRASQ61K co-occurring mutations in tumor samples taken at progression. Combining these findings with those previously reported by Nazarian [95] and McArthur [97], among 36 patients analyzed, five patients (14\%) had an NRAS mutation in a progressive lesion. This further supports the hypothesis by Nazarian et al. [95] that the NRAS mutation is one mechanism of escape from vemurafenib therapy.

Overall, the above reported data suggest that: (1) A concomitant baseline mutation in the upstream NRAS oncogene is rare but may result in early lack of clinical benefit to BRAFi; (2) RAS mutation is a common mechanism of acquired resistance; (3) whether a combination therapy with other targeted agents could overcome resistance remains to be elucidated. 
Table 4

RAS target in locally advanced or metastatic melanoma: ongoing clinical trials (www.clinicaltrials.gov accessed January 26, 2014).

\begin{tabular}{|c|c|c|c|c|}
\hline Drug & Phase & Trial & Disease(s) & Primary outcome measures \\
\hline \multicolumn{5}{|l|}{ Monotherapy non-randomized } \\
\hline MEK162 & II & NCT01320085 & $\begin{array}{l}\text { BRAF or NRAS } \\
\text { Mutated melanoma }\end{array}$ & ORR \\
\hline RAF265 & II & NCT00304525 & Melanoma & $\begin{array}{l}\text { MTD } \\
\text { DLT } \\
\text { Association mutations in } \\
\text { NRAS/clinical response }\left({ }^{\circ}\right)\end{array}$ \\
\hline Selumetinib (AZD6244) & II & NCT00866177 & $\begin{array}{l}\text { BRAF or NRAS } \\
\text { Mutated melanoma }\end{array}$ & Anti-tumor response \\
\hline \multicolumn{5}{|l|}{ Monotherapy randomized } \\
\hline Pimasertib versus dacarbazina & II & NCT01693068 & NRAS mutated melanoma & PFS \\
\hline MEK162 versus dacarbazine & III & NCT01763164 & NRAS mutated melanoma & PFS \\
\hline AZD6244 versus temozolamide & II & NCT00338130 & Melanoma & $\begin{array}{l}\text { PFS } \\
\text { ORR* } \\
\text { TTD } \\
\text { Duration of response } \\
\text { Assessment of the efficacy of } \\
\text { AZD6244 versus } \\
\text { temozolomide BRAF or } \\
\text { NRAS MM patients }\left(^{\circ}\right)\end{array}$ \\
\hline \multicolumn{5}{|c|}{ Combination therapy non-randomized } \\
\hline BKM120 + MEK162 & I & NCT01363232 & $\begin{array}{l}\text { EGFR mutant NSCLC in PD } \\
\text { on EGFR inhibitors } \\
\text { Triple negative breast cancer } \\
\text { Pancreatic cancer } \\
\text { CRC } \\
\text { Melanoma } \\
\text { NSCLC, with KRAS, NRAS, } \\
\text { and/or BRAF mutations }\end{array}$ & DLT \\
\hline $\begin{array}{l}\text { Trametinib } \\
\qquad(\text { GSK1120212) + GSK2141795 }\end{array}$ & II & NCT01941927 & BRAF wt melanoma & $\begin{array}{l}\text { ORR* in patients with either } \\
\text { mutated NRAS or wt } \\
\text { NRAS/wt BRAF M }\end{array}$ \\
\hline $\begin{array}{l}\text { RAF inhibitor (BMS- } \\
\text { 908662) + immunotherapy } \\
\text { (ipilimumab) }\end{array}$ & I & NCT01245556 & Melanoma & $\begin{array}{l}\text { Toxicity } \\
\text { PD will be assessed by } \\
\text { evaluating markers of } \\
\text { RAS/RAF pathway activity } \\
\left(^{\circ}\right)\end{array}$ \\
\hline $\begin{array}{l}\text { PI3K/mTOR inhibitor } \\
\text { BEZ235 + MEK1/2 inhibitor } \\
\text { MEK162 }\end{array}$ & $\mathrm{Ib}$ & NCT01337765 & $\begin{array}{l}\text { EGFR mutant NSCLC in PD } \\
\text { on EGFR inhibitors } \\
\text { Triple negative breast cancer } \\
\text { Pancreatic cancer } \\
\text { Colorectal cancer } \\
\text { Melanoma } \\
\text { NSCLC } \\
\text { Other advanced solid tumors } \\
\text { with KRAS, NRAS, and/or } \\
\text { BRAF mutations }\end{array}$ & Incidence of DLT \\
\hline LEE011 + MEK162 & $\mathrm{Ib}$ & NCT01781572 & NRAS mutated melanoma & $\begin{array}{l}\text { Incidence of DLT } \\
\text { ORR* }\end{array}$ \\
\hline
\end{tabular}

MTD: maximum tolerated dose; EAS: ectopic ACTH secreting; wt: wild type; NR: not reported; ORR: overall response rate; PFS: progression free survival; TTD: time to death; DLT: dose limiting toxicity; ORR*: objective response rate; CRC: colorectal cancer; $\left({ }^{\circ}\right)$ : secondary outcome measures.

The importance of RAS in melanoma deserves clinical and biological investigation to optimize treatment of locally advanced and metastatic melanoma. Although, in the last two decades, progress has been slow, there are now a variety of therapeutic strategies that are primed for clinical investigation. Table 4 summarizes ongoing trials in which RAS, and preferentially NRAS, has been selected as a target.

\section{Future directions}

Thirty years of basic, clinical and translational research have produced a large amount of knowledge pertaining to the RAS oncogene family (Fig. 4). The prevalence of RAS mutations, but also the high number of RAS activators and effectors identified in mammalian cells place the RAS 


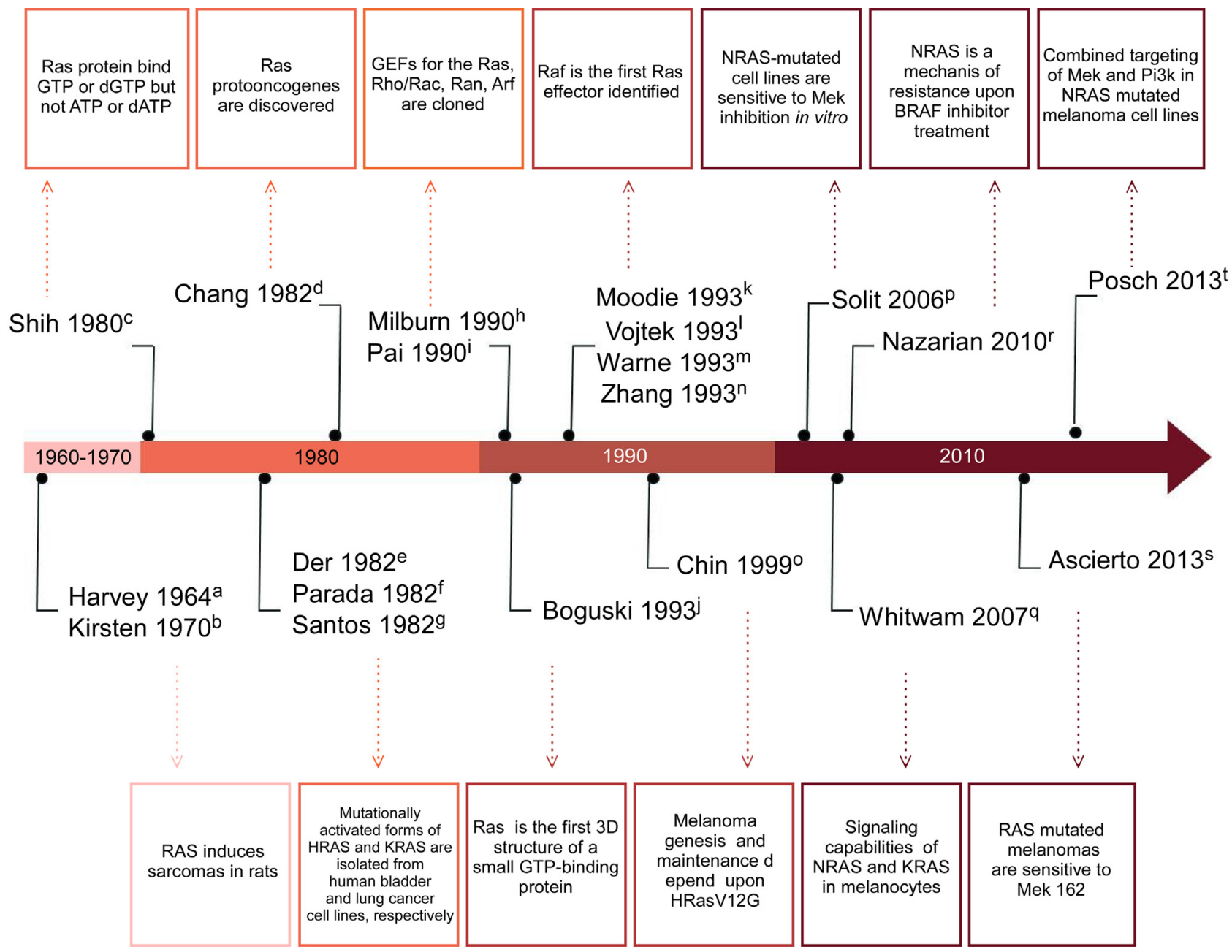

Fig. 4. Timeline of key advances in NRAS clinical and translational research. (a) Harvey et al. (1964) [97]; (b) Kirsten et al. (1970) [98]; (c) Shih et al. (1980) [99]; (d) Chang et al. (1982) [2,3], (e) Der et al. (1982) [4], (f) Parada et al. (1982) [5], (g) Santos et al. (1982) [100], (h) Milburn et al. (1990) [103]; (i) Pai et al. (1990) [102]; (j) Boguski et al. (1993) [101]; (k) Moodie et al. (1993) [9]; (1) Vojtek et al. (1993) [10]; (m) Warne et al. (1993) [11], (n) Zhang et al. (1993) [12]; (o) Chin et al. (1999) [22]; (p) Solit et al. (2006) [86]; (q) Nazarian et al. (2010) [90]; (r) Whitwam et al. (2007) [37]; (s) Ascierto et al. (2013) [87], (t) Posch et al. (2013) [89].

proteins at the crossroads of several signaling networks. Nevertheless, this extensive knowledge has not yet translated into clinically effective therapies for melanomas expressing mutant forms of RAS.

As RAS is mutated in $15-20 \%$ of melanomas, priority actions are needed:

1. Future studies should focus on co-extinction strategies other than reinforcing inhibition of MAPK signaling.

2. Inhibition of the activated downstream cascades including MAPK, PI3K, PLC, RAL should be pursued in preclinical and early phase clinical studies.

3. Most of the downstream targets are not tumor specific therapies and bear the risk of severe side effects. Hence, well-designed clinical studies with appropriate pharmacokinetics and pharmacodynamic end point between combination therapies are needed.

4. MEK inhibitors as monotherapy should be validated in prospective, randomized phase III studies.

\section{Reviewers}

Olivier Michielin, MD, PhD, CHUV - Multidisciplinary Oncology Center (CePO), UNIL - University of Lausanne, Lausanne, Switzerland.

Matteo Carlino, PhD, Westmead Institute of Cancer Research, The University of Sydney, Australia.

\section{References}

[1] Malumbres M, Barbacid M. RAS oncogenes: the first 30 years. Nat Rev Cancer 2003;3:459-65.

[2] Chang EH, Furth ME, Scolnick EM, Lowy DR. Tumorigenic transformation of mammalian cells induced by a normal human gene homologous to the oncogene of Harvey murine sarcoma virus. Nature 1982;297:479-83.

[3] Chang EH, Gonda MA, Ellis RW, Scolnick EM, Lowy DR. Human genome contains four genes homologous to transforming genes of Harvey and Kirsten murine sarcoma viruses. Proc Natl Acad Sci U S A 1982;79:4848-52. 
[4] Der CJ, Krontiris TG, Cooper GM. Transforming genes of human bladder and lung carcinoma cell lines are homologous to the ras genes of Harvey and Kirsten sarcoma viruses. Proc Natl Acad Sci U S A 1982;79:3637-40.

[5] Parada LF, Tabin CJ, Shih C, Weinberg RA. Human EJ bladder carcinoma oncogene is homologue of Harvey sarcoma virus ras gene. Nature 1982;297:474-8.

[6] Shimizu K, Goldfarb M, Suard Y, et al. Three human transforming genes are related to the viral ras oncogenes. Proc Natl Acad Sci U S A 1983;80:2112-6.

[7] Henis YI, Hancock JF, Prior IA. Ras acylation, compartmentalization and signaling nanoclusters. Mol Membr Biol 2009;26:80-92 [Review].

[8] Mor A, Philips MR. Compartmentalized Ras/MAPK signaling. Annu Rev Immunol 2006;24:771-800

[9] Moodie SA, Willumsen BM, Weber MJ, Wolfman A. Complexes of Ras.GTP with Raf-1 and mitogen-activated protein kinase kinase. Science 1993;260:1658-61.

[10] Vojtek AB, Hollenberg SM, Cooper JA. Mammalian Ras interacts directly with the serine/threonine kinase Raf. Cell 1993;74: 205-14.

[11] Warne PH, Viciana PR, Downward J. Direct interaction of Ras and the amino-terminal region of Raf-1 in vitro. Nature 1993;364:352-5.

[12] Zhang XF, Settleman J, Kyriakis JM, et al. Normal and oncogenic p21ras proteins bind to the amino-terminal regulatory domain of cRaf-1. Nature 1993;364:308-13.

[13] Seger R, Krebs EG. The MAPK signaling cascade. FASEB J 1995;9:726-35.

[14] Rodriguez-Viciana P, Warne PH, Dhand R, et al. Phosphatidylinositol3-OH kinase as a direct target of Ras. Nature 1994;370:527-32.

[15] Engelman JA, Luo J, Cantley LC. The evolution of phosphatidylinositol 3-kinases as regulators of growth and metabolism. Nat Rev Genet 2006;7:606-19.

[16] Mandalà M, Voit C. Targeting BRAF in melanoma: biological and clinical challenges. Crit Rev Oncol Hematol 2013;87:239-55.

[17] Feramisco JR, Gross M, Kamata T, Rosenberg M, Sweet RW. Microinjection of the oncogene form of the human H-ras (T-24) protein results in rapid proliferation of quiescent cells. Cell 1984;38:109-17.

[18] Hanahan D, Weinberg RA. Hallmarks of cancer: the next generation. Cell 2011;144:646-74

[19] Finco TS, Westwick JK, Norris JL, Beg AA, Der CJ, Baldwin Jr AS. Oncogenic Ha-Ras-induced signaling activates NF-kappaB transcriptional activity, which is required for cellular transformation. J Biol Chem 1997;272:24113-6.

[20] Westwick JK, Cox AD, Der CJ, et al. Oncogenic Ras activates c-Jun via a separate pathway from the activation of extracellular signalregulated kinases. Proc Natl Acad Sci U S A 1994;91:6030-4.

[21] Winston JT, Coats SR, Wang YZ, Pledger WJ. Regulation of the cell cycle machinery by oncogenic ras. Oncogene 1996;12:127-34.

[22] Chin L, Tam A, Pomerantz J, et al. Essential role for oncogenic Ras in tumour maintenance. Nature 1999;400:468-72.

[23] Johannessen CM, Reczek EE, James MF, Brems H, Legius E, Cichowski K. The NF1 tumor suppressor critically regulates TSC2 and mTOR. Proc Natl Acad Sci U S A 2005;102:8573-8.

[24] Semenza GL. Hypoxia and cancer. Cancer Metastasis Rev 2007;26:223-4.

[25] Chiaradonna F, Sacco E, Manzoni R, Giorgio M, Vanoni M, Alberghina L. Ras-dependent carbon metabolism and transformation in mouse fibroblasts. Oncogene 2006;25:5391-404.

[26] Kranenburg O, Gebbink MF, Voest EE. Stimulation of angiogenesis by Ras proteins. Biochim Biophys Acta 2004;1654:23-37.

[27] Tsujii M, Kawano S, Tsuji S, Sawaoka H, Hori M, DuBois RN. Cyclooxygenase regulates angiogenesis induced by colon cancer cells. Cell 1998;93:705-16.

[28] Ancrile BB, O'Hayer KM, Counter CM. Oncogenic ras-induced expression of cytokines: a new target of anti-cancer therapeutics. Mol Interv 2008;8:22-7.
[29] Blasi F, Carmeliet P. uPAR: a versatile signalling orchestrator. Nat Rev Mol Cell Biol 2002;3:932-43.

[30] Seliger B, Harders C, Wollscheid U, Staege MS, Reske-Kunz AB, Huber C. Suppression of MHC class I antigens in oncogenic transformants: association with decreased recognition by cytotoxic $\mathrm{T}$ lymphocytes. Exp Hematol 1996;24:1275-9.

[31] Kubuschok B, Neumann F, Breit R, et al. Naturally occurring T-cell response against mutated p21 ras oncoprotein in pancreatic cancer. Clin Cancer Res 2006;12:1365-72.

[32] Tran Thang NN, Derouazi M, Philippin G, et al. Immune infiltration of spontaneous mouse astrocytomas is dominated by immunosuppressive cells from early stages of tumor development. Cancer Res 2010;70:4829-39.

[33] Frisch SM, Francis H. Disruption of epithelial cell-matrix interactions induces apoptosis. J Cell Biol 1994;124:619-26.

[34] Campbell PM, Der CJ. Oncogenic Ras and its role in tumor cell invasion and metastasis. Semin Cancer Biol 2004:14:105-14.

[35] Giehl K. Oncogenic Ras in tumour progression and metastasis. Biol Chem 2005;386:193-205.

[36] Chin L, Garraway LA, Fisher DE. Malignant melanoma: genetics and therapeutics in the genomic era. Genes Dev 2006;20:2149-82.

[37] Whitwam T, Vanbrocklin MW, Russo ME, et al. Differential oncogenic potential of activated RAS isoforms in melanocytes. Oncogene 2007;26:4563-70

[38] Prior IA, Hancock JF. Compartmentalization of Ras proteins. J Cell Sci 2001;114(Pt 9):1603-8.

[39] Ross AL, Sanchez MI, Grichnik JM. Molecular nevogenesis. Dermatol Res Pract 2011:2011:463184.

[40] Ichii-Nakato N, Takata M, Takayanagi S, et al. High frequency of BRAFV600E mutation in acquired nevi and small congenital nevi, but low frequency of mutation in medium-sized congenital nevi. J Invest Dermatol 2006;126:2111-8.

[41] Dessars B, De Raeve LE, Morandini R, et al. Genotypic and gene expression studies in congenital melanocytic nevi: insight into initial steps of melanotumorigenesis. J Invest Dermatol 2009;129: $139-47$.

[42] Charbel C, Fontaine RH, Malouf GG, et al. NRAS mutation is the sole recurrent somatic mutation in large congenital melanocytic nevi. J Invest Dermatol 2013;(October).

[43] Ichii-Nakato N1, Takata M, Takayanagi S, et al. High frequency of BRAFV600E mutation in acquired nevi and small congenital nevi, but low frequency of mutation in medium-sized congenital nevi. J Invest Dermatol 2006;126:2111-8.

[44] Bauer J, Curtin JA, Pinkel D, Bastian BC. Congenital melanocytic nevi frequently harbor NRAS mutations but no BRAF mutations. J Invest Dermatol 2007;127:179-82.

[45] Phadke PA, Rakheja D, Le LP, et al. Proliferative nodules arising within congenital melanocytic nevi: a histologic, immunohistochemical, and molecular analyses of 43 cases. Am J Surg Pathol 2011;35:656-69.

[46] Pedersen M, Küsters-Vandevelde HV, Viros A, et al. Primary melanoma of the CNS in children is driven by congenital expression of oncogenic NRAS in melanocytes. Cancer Discov 2013;3:458-69.

[47] Gessi M, Hammes J, Lauriola L, et al. GNA11 and N-RAS mutations: alternatives for MAPK pathway activating GNAQ mutations in primary melanocytic tumours of the central nervous system. Neuropathol Appl Neurobiol 2013;39:417-25.

[48] Kinsler VA, Thomas AC, Ishida M, et al. Multiple congenital melanocytic nevi and neurocutaneous melanosis are caused by postzygotic mutations in codon 61 of NRAS. J Invest Dermatol 2013;133:2229-36.

[49] Carr J, Mackie RM. Point mutations in the N-ras oncogene in malignant melanoma and congenital naevi. Br J Dermatol 1994;131:72-7.

[50] Jafari M, Papp T, Kirchner S, et al. Analysis of ras mutations in human melanocytic lesions: activation of the ras gene seems to be associated with the nodular type of human malignant melanoma. J Cancer Res Clin Oncol 1995;121:23-30. 
[51] Albino AP, Nanus DM, Mentle IR, et al. Analysis of ras oncogenes in malignant melanoma and precursor lesions: correlation of point mutations with differentiation phenotype. Oncogene 1989;4:1363-74.

[52] Eskandarpour M, Hashemi J, Kanter L, Ringborg U, Platz A, Hansson J. Frequency of UV-inducible NRAS mutations in melanomas of patients with germline CDKN2A mutations. J Natl Cancer Inst 2003;95:790-8.

[53] Tschandl P, Berghoff AS, Preusser M, et al. NRAS and BRAF mutations in melanoma-associated nevi and uninvolved nevi. PLOS ONE 2013;8:e69639.

[54] Curtin JA, Fridlyand J, Kageshita T, et al. Distinct sets of genetic alterations in melanoma. N Engl J Med 2005;353:2135-47.

[55] Lee JH, Choi JW, Kim YS. Frequencies of BRAF and NRAS mutations are different in histological types and sites of origin of cutaneous melanoma: a meta-analysis. Br J Dermatol 2011;164:776-84.

[56] Lovly CM, Dahlman KB, Fohn LE, et al. Routine multiplex mutational profiling of melanomas enables enrollment in genotype-driven therapeutic trials. PLOS ONE 2012;7:e35309.

[57] Henary H, Hong DS, Falchook GS, et al. Melanoma patients in a phase I clinic: molecular aberrations, targeted therapy and outcomes. Ann Oncol 2013;24:2158-65.

[58] Platz A, Egyhazi S, Ringborg U, Hansson J. Human cutaneous melanoma; a review of NRAS and BRAF mutation frequencies in relation to histogenetic subclass and body site. Mol Oncol 2008;1:395-405.

[59] Akslen LA, Puntervoll H, Bachmann IM, et al. Mutation analysis of the EGFR-NRAS-BRAF pathway in melanomas from black Africans and other subgroups of cutaneous melanoma. Melanoma Res 2008;18:29-35.

[60] Si L, Kong Y, Xu X, et al. Prevalence of BRAF V600E mutation in Chinese melanoma patients: large scale analysis of BRAF and NRAS mutations in a 432-case cohort. Eur J Cancer 2012;48:94-100.

[61] Edlundh-Rose E, Egyházi S, Omholt K, et al. NRAS and BRAF mutations in melanoma tumours in relation to clinical characteristics: a study based on mutation screening by pyrosequencing. Melanoma Res 2006;16:471-8.

[62] Ball NJ, Yohn JJ, Morelli JG, Norris DA, Golitz LE, Hoeffler JP. Ras mutations in human melanoma: a marker of malignant progression. J Invest Dermatol 1994;102:285-90.

[63] Ellerhorst JA, Greene VR, Ekmekcioglu S, et al. Clinical correlates of NRAS and BRAF mutations in primary human melanoma. Clin Cancer Res 2011;17:229-35.

[64] Griewank KG, Westekemper H, Murali R, et al. Conjunctival melanomas harbor BRAF and NRAS mutations and copy number changes similar to cutaneous and mucosal melanomas. Clin Cancer Res 2013;19:3143-52.

[65] Turri-Zanoni M, Medicina D, Lombardi D, et al. Sinonasal mucosal melanoma: molecular profile and therapeutic implications from a series of 32 cases. Head Neck 2013;35:1066-77.

[66] Sekine S, Nakanishi Y, Ogawa R, Kouda S, Kanai Y. Esophageal melanomas harbor frequent NRAS mutations unlike melanomas of other mucosal sites. Virchows Arch 2009;454:513-7.

[67] Dutton-Regester K, Kakavand H, Aoude LG, et al. Melanomas of unknown primary have a mutation profile consistent with cutaneous sun-exposed melanoma. Pigment Cell Melanoma Res 2013;26:852-60.

[68] Devitt B, Liu W, Salemi R, et al. Clinical outcome and pathological features associated with NRAS mutation in cutaneous melanoma. Pigment Cell Melanoma Res 2011;24:666-72.

[69] Nagore E, Hacker E, Martorell-Calatayud A, et al. Prevalence of BRAF and NRAS mutations in fast-growing melanomas. Pigment Cell Melanoma Res 2013;26:429-31.

[70] van Elsas A, Zerp SF, van der Flier S, et al. Relevance of ultravioletinduced $\mathrm{N}$-ras oncogene point mutations in development of primary human cutaneous melanoma. Am J Pathol 1996;149:883-93.

[71] Demunter A, Stas M, Degreef H, De Wolf-Peeters C, van den Oord JJ. Analysis of N- and K-ras mutations in the distinctive tumor progression phases of melanoma. J Invest Dermatol 2001;117: 1483-9.

[72] Treatment of early-stage breast cancer. NIH consensus conference. JAMA 1991;265:391-5.

[73] Omholt K, Platz A, Kanter L, Ringborg U, Hansson J. NRAS and BRAF mutations arise early during melanoma pathogenesis and are preserved throughout tumor progression. Clin Cancer Res 2003;9:6483-8.

[74] Ugurel S, Thirumaran RK, Bloethner S, et al. B-RAF and N-RAS mutations are preserved during short time in vitro propagation and differentially impact prognosis. PLoS ONE 2007;2:e236.

[75] Birkeland E, Busch C, Berge EO, et al. Low BRAF and NRAS expression levels are associated with clinical benefit from DTIC therapy and prognosis in metastatic melanoma. Clin Exp Metastasis 2013;30:867-76.

[76] Demunter A, Ahmadian MR, Libbrecht L, et al. A novel Nras mutation in malignant melanoma is associated with excellent prognosis. Cancer Res 2001;61:4916-22.

[77] Houben R, Becker JC, Kappel A, et al. Constitutive activation of the Ras-Raf signaling pathway in metastatic melanoma is associated with poor prognosis. J Carcinog 2004;3:6.

[78] Jakob JA, Bassett Jr RL, Ng CS, et al. NRAS mutation status is an independent prognostic factor in metastatic melanoma. Cancer 2012;118:4014-23.

[79] Omholt K, Karsberg S, Platz A, Kanter L, Ringborg U, Hansson J. Screening of N-ras codon 61 mutations in paired primary and metastatic cutaneous melanomas: mutations occur early and persist throughout tumor progression. Clin Cancer Res 2002;8:3468-74.

[80] Bucheit AD, Syklawer E, Jakob JA, et al. Clinical characteristics and outcomes with specific BRAF and NRAS mutations in patients with metastatic melanoma. Cancer 2013 Nov 1;119:3821-9.

[81] Mann GJ, Pupo GM, Campain AE, et al. BRAF mutation, NRAS mutation, and the absence of an immune-related expressed gene profile predict poor outcome in patients with stage III melanoma. J Invest Dermatol 2013;133:509-17.

[82] Akslen LA, Angelini S, Straume O, et al. BRAF and NRAS mutations are frequent in nodular melanoma but are not associated with tumor cell proliferation or patient survival. J Invest Dermatol 2005;125:312-7.

[83] Ekedahl H, Cirenajwis H, Harbst K, et al. The clinical significance of BRAF and NRAS mutations in a clinic-based metastatic melanoma cohort. Br J Dermatol 2013;169:1049-55.

[84] Banerji U, Affolter A, Judson I, Marais R, Workman P. BRAF and NRAS mutations in melanoma: potential relationships to clinical response to HSP90 inhibitors. Mol Cancer Ther 2008;7:737-9.

[85] Joseph RW, Sullivan RJ, Harrell R, et al. Correlation of NRAS mutations with clinical response to high-dose IL-2 in patients with advanced melanoma. J Immunother 2012;35:66-72.

[86] Patel SP, Lazar AJ, Papadopoulos NE, et al. Clinical responses to selumetinib (AZD6244; ARRY-142886)-based combination therapy stratified by gene mutations in patients with metastatic melanoma. Cancer 2013;119:799-805.

[87] Solit DB, Garraway LA, Pratilas CA, et al. BRAF mutation predicts sensitivity to MEK inhibition. Nature 2006;439:358-62.

[88] Ascierto PA, Schadendorf D, Berking C, et al. MEK162 for patients with advanced melanoma harbouring NRAS or Val600 BRAF mutations: a non-randomised, open-label phase 2 study. Lancet Oncol 2013;14:249-56.

[89] Winski S, Anderson D, Bouhana K, et al. MEK162 (ARRY-162), a novel MEK 1/2 inhibitor, inhibits tumor growth regardless of KRas/Raf pathway mutations. In: Proceedings of the 22nd EORTCNCI-AACR symposium on molecular targets and cancer therapeutics. 2010.

[90] Yeh TC, Marsh V, Bernat BA, et al. Biological characterization of ARRY-142886 (AZD6244), a potent, highly selective mitogenactivated protein kinase kinase 1/2 inhibitor. Clin Cancer Res 2007;13:1576-83. 
[91] Ostrem JM, Peters U, Sos ML, Wells JA, Shokat KM. K-Ras(G12C) inhibitors allosterically control GTP affinity and effector interactions. Nature 2013;503:548-51.

[92] Dahlman KB, Xia J, Hutchinson K, et al. BRAF(L597) mutations in melanoma are associated with sensitivity to MEK inhibitors. Cancer Discov 2012;2:791-7.

[93] Posch C, Moslehi H, Feeney L, et al. Combined targeting of MEK and PI3K/mTOR effector pathways is necessary to effectively inhibit NRAS mutant melanoma in vitro and in vivo. Proc Natl Acad Sci U S A 2013;110:4015-20.

[94] Johnson DB, Lovly CM, Flavin M, et al. NRAS mutation: a potential biomarker of clinical response to immune-based therapies in metastatic melanoma (MM). J Clin Oncol 2013;31(Supppl.) [abstr 9019].

[95] Nazarian R, Shi H, Wang Q, et al. Melanomas acquire resistance to B-RAF(V600E) inhibition by RTK or N-RAS upregulation. Nature 2010;468:973-7.

[96] Trunzer K, Pavlick AC, Schuchter L, et al. Pharmacodynamic effects and mechanisms of resistance to vemurafenib in patients with metastatic melanoma. J Clin Oncol 2013:31:1767-74.

[97] McArthur G, Ribas A, Chapman PB, et al. Molecular analyses from a phase I trial of vemu-rafenib to study mechanism of action (MOA) and resistance in repeated biopsies from BRAF mutation positive metastatic melanoma patients (pts). J Clin Oncol 2011;29(Suppl.) [abstr 8502].

[98] Poulikakos PI, Persaud Y, Janakiraman M, et al. RAF inhibitor resistance is mediated by dimerization of aberrantly spliced BRAF(V600E). Nature 2011;480:387-90.

[99] Wagle N, Van Allen EM, Treacy DJ, et al. MAP kinase pathway alterations in BRAF-mutant melanoma patients with acquired resistance to combined RAF/MEK inhibition. Cancer Discov 2014;4:61-8.

[100] Van Allen EM, Wagle N, Sucker A, et al. The genetic landscape of clinical resistance to RAF inhibition in metastatic melanoma. Cancer Discov 2014;4:94-109.

[101] Rizos H, Menzies AM, Pupo GM, et al. BRAF inhibitor resistance mechanisms in metastatic melanoma: spectrum and clinical impact. Clin Cancer Res 2014;20:1965-77.

[102] Dumaz N, Hayward R, Martin J, et al. In melanoma, RAS mutations are accompanied by switching signaling from BRAF to CRAF and disrupted cyclic AMP signaling. Cancer Res 2006;66:9483-91.

[103] Su F, Bradley WD, Wang Q, et al. Resistance to selective BRAF inhibition can be mediated by modest upstream pathway activation. Cancer Res 2012;72:969-78.

[104] Sosman JA, Kim KB, Schuchter L, et al. Survival in BRAF V600mutant advanced melanoma treated with vemurafenib. N Engl J Med 2012;366:707-14.

\section{Biographies}

Mario Mandalà is currently a medical oncologist in the Unit of Medical Oncology, Papa Giovanni XXIII Hospital in
Bergamo, Italy. He is in charge of the Clinical and Translational Research Unit. He received his MD from the Catholic University in Rome, Italy in 1995 . He has completed residencies in Medical Oncology at the Catholic University in Rome as well as at Milan University and the European Institute of Oncology in Milan, Italy. He also obtained diplomas in Medical Oncology and Haematology from Milan University in 2000 and 2005, respectively. His research interests include clinical and translational research on cancer and thrombosis. His main oncological research focuses on gastrointestinal cancer and melanoma. He is a full member of the European Society of Medical Oncology. He has leador co-authored many scientific papers and is a reviewer for several journals, including Lancet Oncology, Cancer, British Journal of Cancer, Annals of Oncology, Cancer Treatment Review, Journal of Thrombosis and Haemostasis, Thrombosis and Hemostasis, Arteriosclerosis-Thrombosis and Vascular Biology, Critical Reviews in Oncology and Haematology.

Daniela Massi, $\mathrm{MD}, \mathrm{PhD}$, is associate professor of pathology at the University of Florence Medical School, Italy. Her pathology training includes a dermatopathology fellowship at the Institute for Dermatopathology, Thomas Jefferson University, Philadelphia, PA, under the direction of A. Bernard Ackerman. She then received a post-doctoral research fellowship from the American-Italian Cancer Foundation (A.I.C.F.) with a research program in cutaneous melanoma. She has been member of the Executive Committee of the International Society of Dermatopathology (1997-2003), Chairman of the Dermatopathology Working Group of the European Society of Pathology (2007-2011), and she is currently member of the EORTC Melanoma Pathology Group. She is an associate editor of Virchows Archiv and scientific reviewer for several international scientific journals. Her research interests are focused on skin tumor pathology, and particularly receptor signaling and molecular genetics of melanoma. She has authored more than 200 publications and contributed to the volume 'Pathology \& Genetics of Skin Tumours' of the World Health Organization (WHO) Classification of Tumours series. 